\title{
Scanning Electron Microscopic Features of the Renal Arteries in Indian Goat (Capra hircus) and Pig (Suscrofa domesticus)
}

\author{
B. Padmasri ${ }^{1 *}$, D. Pramod Kumar ${ }^{1}$, G. Purushotham ${ }^{1}$ and K.B.P. Raghavender $^{2}$ \\ ${ }^{1}$ Department of Veterinary Anatomy, CVSc Hyd., Telangana, India \\ ${ }^{2}$ Department of Veterinary Surgery and Radiology, CVSc, Hyd., Telangana, India \\ *Corresponding author
}

\section{A B S T R A C T}

\section{Keywords \\ Renal artery, Goat, Pig \\ Article Info \\ Accepted: \\ 23 March 2018 \\ Available Online: \\ 10 April 2018}

\begin{abstract}
Scanning electron micrographic observations of renal arteries of goat and pig which revealed a thin tunica intima enveloped by packed layer of smooth muscle cells in media in both species. Endothelium was wavy in outline on internal aspect of renal arteries in goats and pigs. It presented cushion like foldings which were aligned across the longitudinal axis of the artery. Outer parts of tunica media were anchored by fine collagen fibrils and elastic fibers to the collagen tissue in adventitia. In case of pig, tunica adventitia of renal arteries was relatively thicker than that of the goat. Internal diameter of pig renal artery was more than the goat renal arteries. Internal elastic membrane was comparatively thin wavy structure with invaginations into the tunica media.
\end{abstract}

\section{Introduction}

Renal artery comprised well developed three layers viz, tunica intima, media and adventitia whose structural proportion varied with the size and function of the particular artery (Vodenicharov and Cirnuchanov, 1995). The endothelium was the only cell type found in the tunica intima while tunica media consisted of pure population of smooh muscle cells and fewer strands of elastic fibers are seen in muscular artery (Pease and Sandra, 1960). The inner elastic membrane is separated into two and occasionally three membranes of various thickness, among which single smooth-muscle fibres are found (Alekseevskih, 1969) which was a normal event in adult humans (Evans, 1960). Outer elastic membrane is of regular thickness (Alekseevskih, 1969). Apart from an outer elastic membrane, some authors have described a collagen and an elastic adventitia (Fourman and Moffat, 1971). The renal artery shows a gradual transition from elastic to muscle type from its enit to hilus (ObsornePellegrin, 1978).

\section{Materials and Methods}

Renal artery samples were collected from twelve adult apparently healthy goats and pigs For SEM studies fresh one cubic mm tissue pieces of renal arteries of goats and pigs were taken and fixed in $2.5 \%$ glutaraldehyde in 0.1 M phosphate buffer ( $\mathrm{pH}$ 7.2) for $24 \mathrm{hrs}$ at $4{ }^{\circ} \mathrm{C}$ and post fixed in $2 \%$ aqueous osmium tetroxide for $4 \mathrm{hrs}$. Post fixation samples were 
dehydrated in series of graded alcohols and dried to critical point drying. Samples were mounted over stubs with double sided carbon conductivity tape and thin layer of gold was coated in automated sputter coater and scanned under Scanning electron microscope.

\section{Results and Discussion}

SEM studies revealed that cross sections of three renal artery segments in both species displayed a thin tunica intima surrounded by a packed layer of smooth muscle cells in media which in turn was enveloped by a network of predominantly collagen and few elastic fibres in outer adventitia (Fig. 1) which was relatively thicker in pig specimens (Fig. 2). Endothelial layer was seen in a wavy pattern on the internal aspect of both species. It appeared cushion like and were aligned across the longitudinal axis of the artery. This wavy cushion like foldings were evenly spaced apart (Figs. 1 and 3) which was akin to the mention of arterial cushions on endothelial wall which helps in directing and regulating the blood flow in organs (Ono et al., 1979; Casellas et al., 1989 in rat renal arteries and vascular casts in eleven different organs respectively). They reported that these arterial cushions were valve like which help in regulating blood flow in smaller vessels.

Approximate average of tunica intima at three places was about $36.7 \mu \mathrm{m}$ and $40 \mu \mathrm{m}$, tunica media was $269 \mu \mathrm{m}$ and $117.9 \mu \mathrm{m}$ and adventitia was about $126 \mu \mathrm{m}$ and $93.3 \mu \mathrm{m}$ (Figs. 4 and 5) in goat and pig respectively. It contained endothelial and sub epithelial connective tissue, Endothelium was a sheet of squamous cell layer which was present in wavy undulating manner and had tiny spaces in between the folds of pig specimens (Fig. 3). The elevations were across the longitudinal axis of the artery and were separated by shallow clefts, which in few places were a little deep (Fig. 6).

Fig.1 Scanning electron micrograph of cross section of renal artery of goat showing three tunics

1 - tunica intima, 2 - tunia media, 3 - tunica adventitia, E - endothelium

(SEM- 70X)

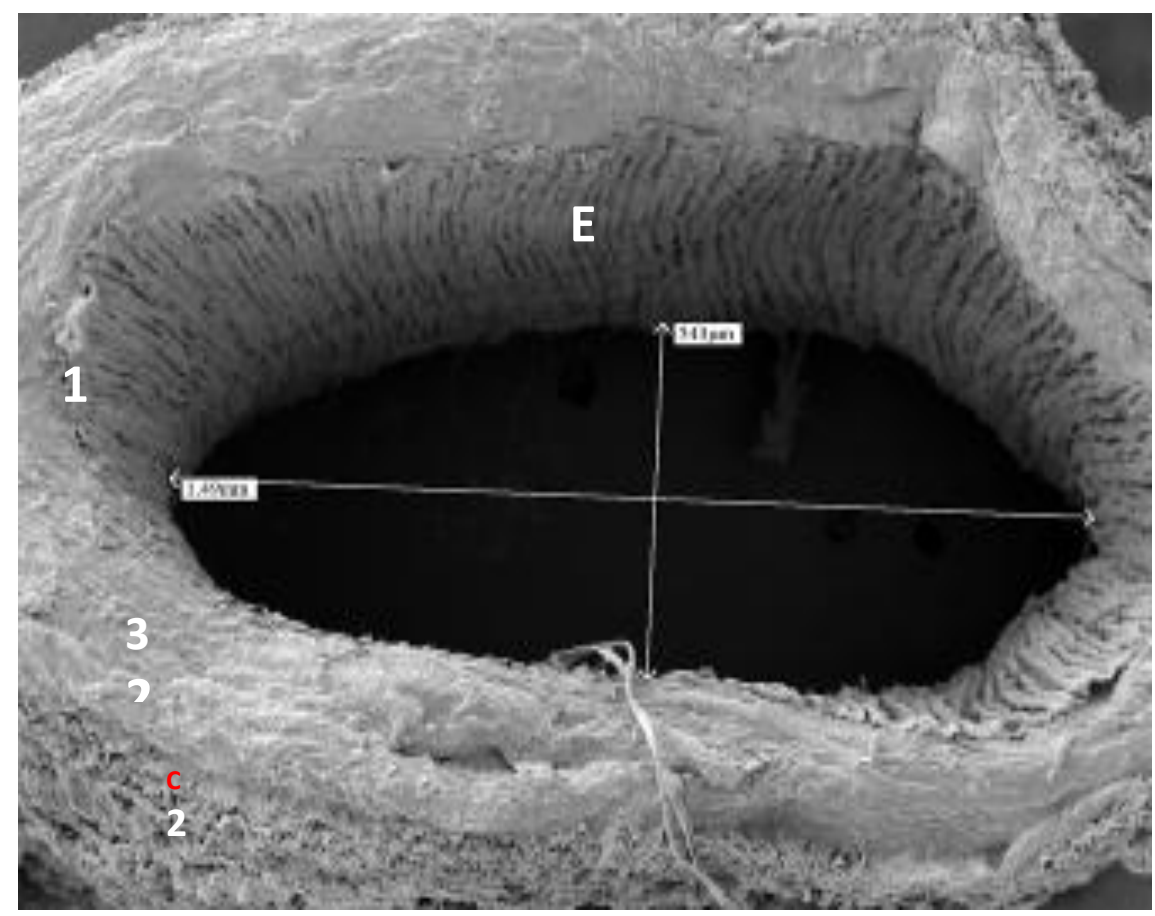


Fig.2 Scanning electron micrograph of cross section of renal artery of pig showing all three layers

1 - tunica intima, 2 - tunica media, 3 - tunica adventitia

$(\mathrm{SEM}-120 \mathrm{X})$

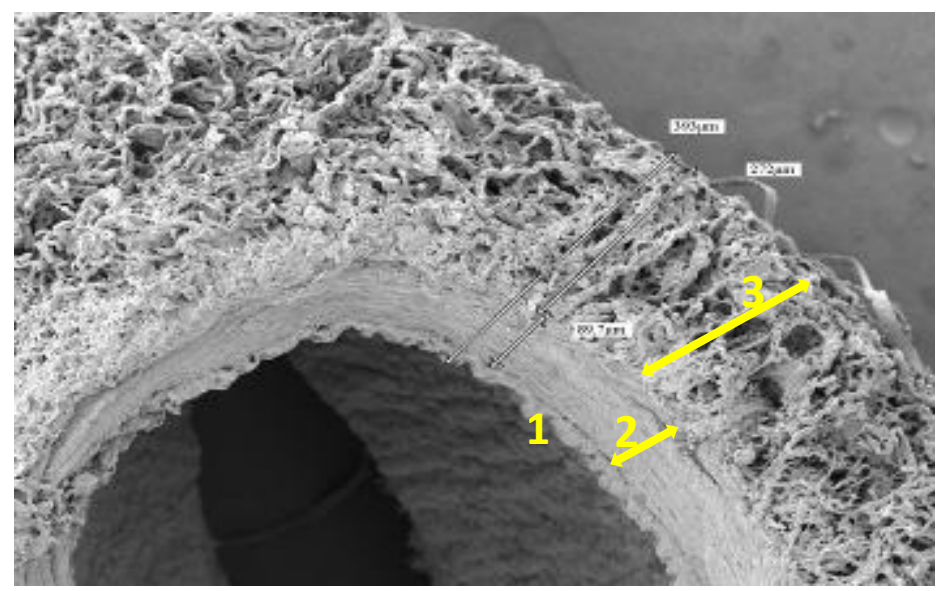

Fig.3 Scanning electron micrograph of cross section of renal artery of pig showing wavy pattern of endothelium $(*)$ and smooth muscle cell (SMC) layers in tunica media

$(\mathrm{SEM}-500 \mathrm{X})$

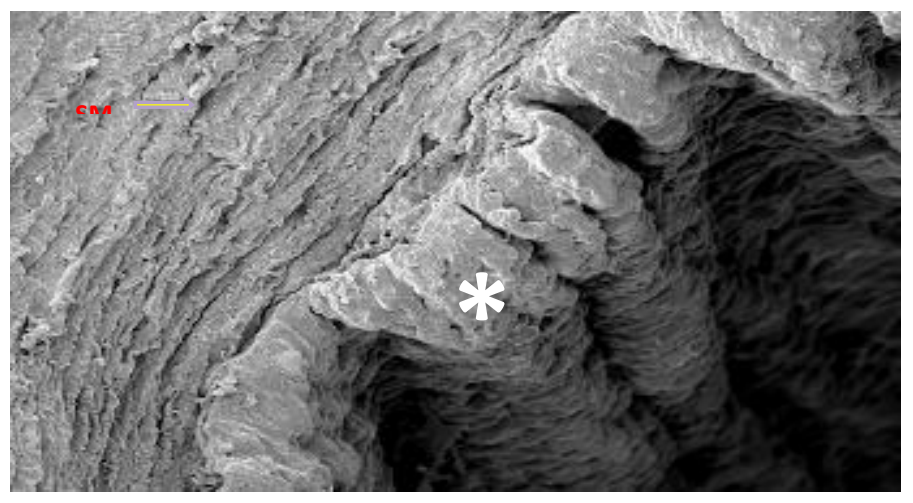

Fig.4 Scanning electron micrograph of cross section of renal artery of goat showing measurements of all three layers

(SEM- 180X)

1 - tunica intima, 2 - tunica media, 3 - tunica adventitia

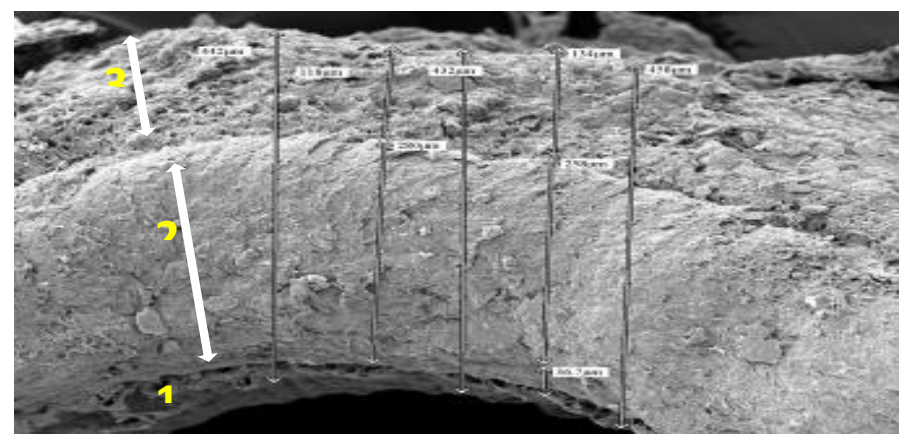


Fig.5 Scanning electron micrograph of renal artery of pig showing measurements of all three layers

$(\mathrm{SEM}-120 \mathrm{X})$

1 - tunica intima, 2 - tunica media, 3 - tunica adventitia

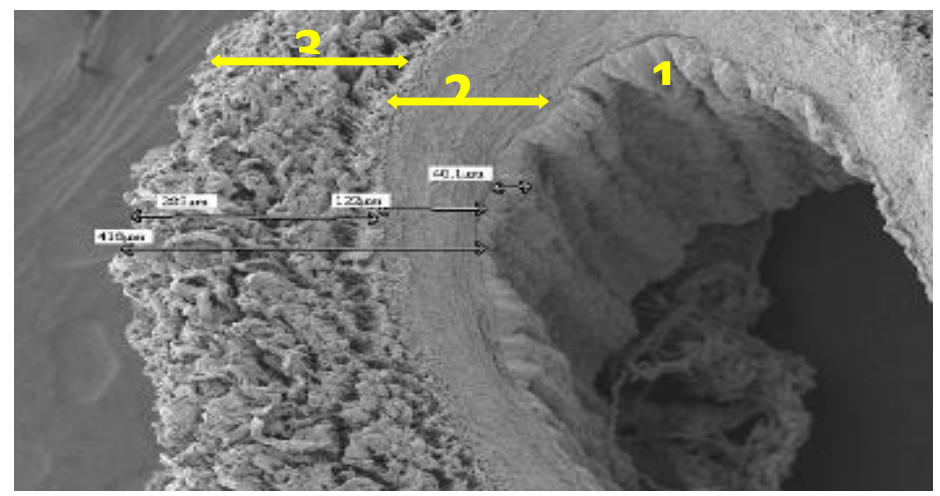

Fig.6 Scanning electron micrograph of renal artery of goat showing wavy endothelium (E) and smooth muscle cells (SMC) in tunica media

$(\mathrm{SEM}-500 \mathrm{X})$

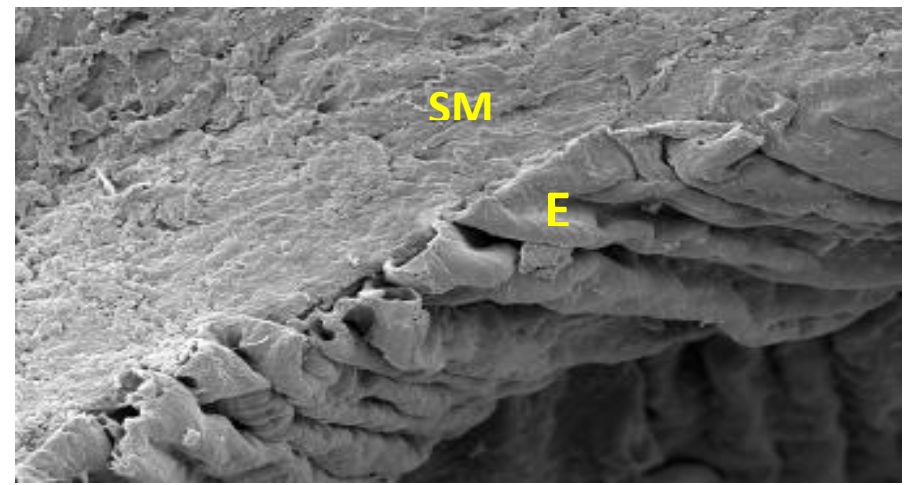

Fig.7 Scanning electron micrograph of renal artery of goat showing deep invaginations (*) of internal elastic membrane $(\rightarrow)$ in some planes

$(\mathrm{SEM}-2500 \mathrm{X})$

E - endothelium

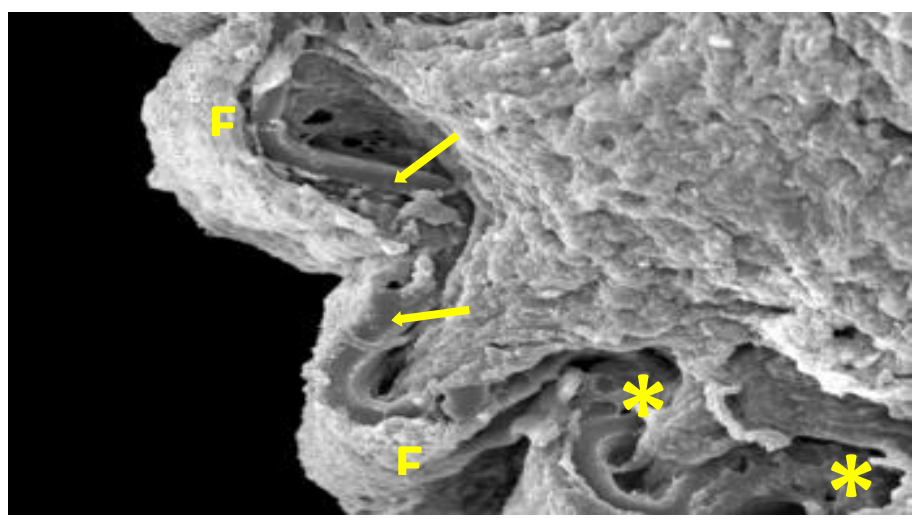


Fig.8 Scanning electron micrograph of cross section of renal artery of goat showing outer elastic laminae $(\rightarrow)$

$(\mathrm{SEM}-1500 \mathrm{X})$

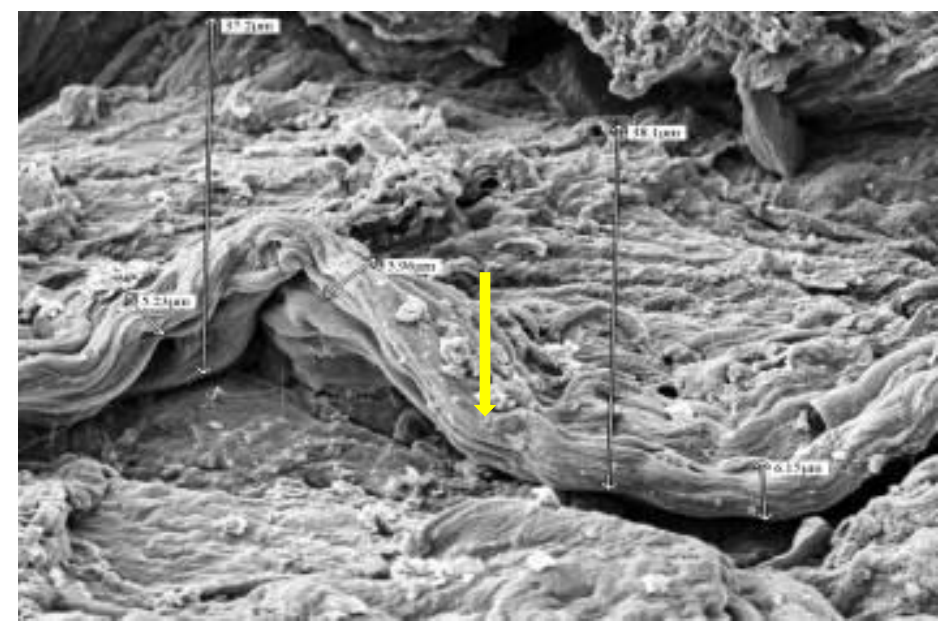

Fig.9 Scanning electron micrograph of cross section of renal artery of pig showing wavy pattern of endothelium (E) and dense collagen fibers in tunica adventitia

$(\rightarrow)$ elastic fibers, $(*)$ collagen fibers

$(\mathrm{SEM}-200 \mathrm{X})$

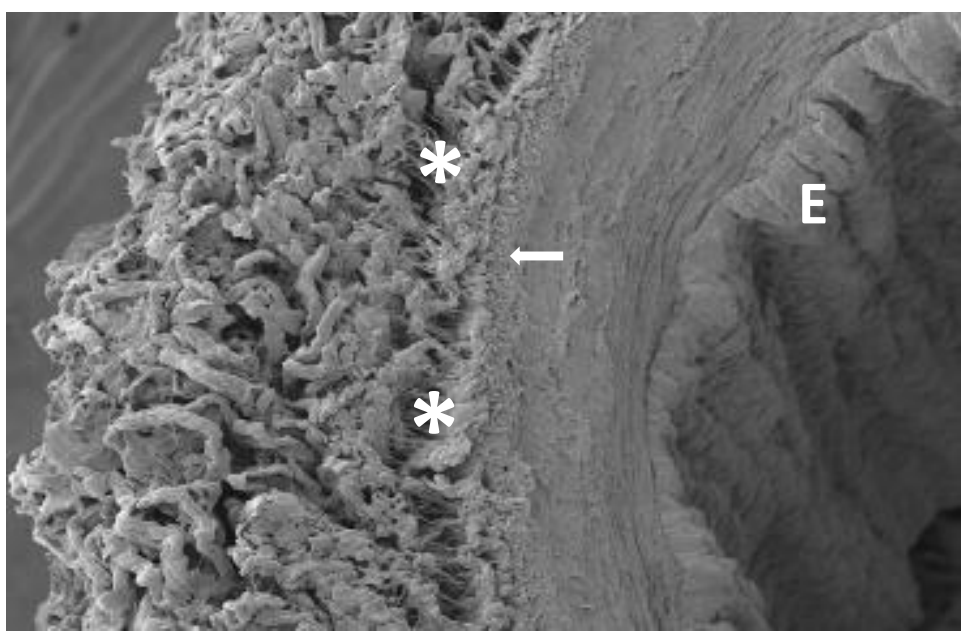

Internal elastic membrane (IEM) was a solid continuous line which was wavy in appearance with deep invaginations in goats (Fig. 7) whereas in pigs it was thin and linear limiting the tunica intima. Below the IEM the media was packed smooth muscle cells in compact layers and few of its fibres predominant collagen fibres and few elastic fibers were seen filling up the troughs in the
IEM (Fig. 3 and 7) where they were arranged spirally in renal artery of rat, similar to those in the aorta which was akin to the findings of the Alekseevskih (1969) and ObsornePellegrin (1978).

Outer elastic lamina (OEL) was two and more stranded in a wavy pattern and was in between the media and outer adventitia (Fig. 
8) beyond the OEL fine collagen fibrils and elastic fibres anchored the collagen tissue in connective tissue of tunica adventitia which had comparatively thick collagen fibers than elastic fibers as a labyrinth network of connective tissue (Fig. 9) in pigs were in total agreement with similar findings in various arteries by Ushiwata and Ushiki (1990) in rat brain; Fujiwara and Uehara (1992) in monkey mesentery, Higuchi et al., (2000) in rat cardiac vessels and Janzen et al., (2000) in human vessels who stated that which probably may help resist the stretching force of vigorously pumping heart.

\section{References}

Alekseevskikh, U. 1969: On some histological peculiarities of the structure of arteries and veins in the kidney in man. Arch. Pathol. 31, 6, 42-46.

Casellas D, Dupont M, Jover B and Mimran A (1989). Scanning electron microscopic study of arterial cushions in rats: Novel application of the corrosion-replication technique. The Anatomical Record, July. 203(3): 419.

Evans, W. 1960: The aetiology of systemic hypertension. British Heart Jour. 22, 1736.

Fourman, J. and D. Moffat, 1971: The Blood Vessels of the Kidney. Oxford, Edinburgh: Blackwell Scientific Pub.

Fuziwata T and Uehara Y (1992). Scanning electron microscopical study of vascular smooth muscle cells of the monkey: Arterial smooth muscle cells. Biomedical Research. 3: 649- 658.
Higuchi K, Hashizume H, Aizawa Y and Ushiki T (2000). Scanning electron microscopic studies of the vascular smooth muscle cells and pericytes in the rat heart. Archives of Histology and Cytology. 63(2): 115-126.

Janzen J, Lanzer P, Rothenberger-Janzen K and Vuong, P. (2000). The transitional zone in the tunica media of renal arteries has a maximal length of 10 millimeters. VASA, 29(3): 168.

Ono H, Mizoguchi K, Ueda Y, Oka K and Iidaka K (1979). Pathomorphological studies on Arterial Cushion. 1. Rat normal kidney. Nihon Jinzo Gakki Shi. March: 31(3):243-51.

Osborne-Pellegrin, M. 1978: Some ultrastructural characteristics of the renal artery and abdominal aorta in the rat. J. Anat. 125, 641- 651.

Pease, D. C., and Molinari, S. (1960). Electron microscopy of muscular arteries; pial vessels of the cat and monkey. Journal of ultrastructure research, 3(4), 447-468.

Ushiwata I and Ushiki T. (1990). Cytoarchitecture of the smooth muscles and pericytes of rat cerebral blood vessels. Journal of Neurosurgery. 73: 82-90.

Vodenicharov, A., and Cirnuchanov, P. (1995). Microscopical and ultrastructural studies of the renal artery in domestic swine. Anatomia, histologia, embryologia, 24(4), 237 240.

\section{How to cite this article:}

Padmasri, B., D. Pramod Kumar, G. Purushotham and Raghavender, K.B.P. 2018. Scanning Electron Microscopic Features of the Renal Arteries in Indian Goat (Capra hircus) and Pig (Suscrofa domesticus). Int.J.Curr.Microbiol.App.Sci. 7(04): 3063-3068.

doi: https://doi.org/10.20546/ijcmas.2018.704.347 